\section{Summary of: Initial management of paediatric dento-alveolar trauma in the permanent dentition: a multi-centre evaluation}

\author{
H. Zaitoun, ${ }_{1}^{1}$ S. North, ${ }_{1}^{2}$ S. Lee, ${ }_{1}^{3}$ S. Albadri, ${ }_{1}^{4}$ S. T. McDonnell, ${ }^{5}$ \\ and H. D. Rodd 6
}

\section{FULL PAPER DETAILS}

1:2,6 Department of Paediatric Dentistry, Charles Clifford Dental Hospital, Wellesley Road, Sheffield, S10 $2 S Z_{i}^{3,4}$ Department of Paediatric Dentistry, Liverpool University Dental Hospital, Pembroke Place, Liverpool, L3 5PS; 5 Unit of Paediatric Dentistry, University Denta Hospital of Manchester, Higher Cambridge Street, Manchester, M15 6FH

${ }^{*}$ Correspondence to: Halla Zaitoun Email: halla.zaitoun@sth.nhs.uk Online article number E11 Refereed Paper - Accepted 7 October 2009 DOI: $10.1038 /$ sj.bdj.2010.254

${ }^{\circ}$ British Dental Journal 2010; 208: E11

Objective To investigate the time lapse prior to provision of emergency dental care and appropriateness of earliest treatment provided for children with dental trauma. Design A multi-regional prospective and cross-sectional survey. Setting Paediatric dental departments of Liverpool, Manchester and Sheffield. Subjects One hundred and fifty referred or emergency paediatric patients with trauma to the permanent incisors. Results One hundred and fifty subjects were recruited. Mean age of the subjects was 11.1 years ( $S D=2.6$; range $=6.2-16.6) ; 100$ were male and 50 were female. The mean time interval from injury until initial presentation to a health care professional was 22.6 hours (SD $=76.1$; range $=0-672$ ). Thirty-six percent of children $(n=54)$ first presented to a general dental practitioner whilst $30 \%(n=45)$ presented to accident and emergency medical staff. Following initial assessment, a further mean time lapse of 8.1 hours (SD = 43.7; range $=0-504$ ) was incurred in 25\% of cases prior to dental referral. In $39 \%$ of subjects ( $n=58 / 150$ ), treatment was considered inappropriate. The most frequent example of inadequate management was failure to protect exposed dentine, which was found for $71 \%(n=24 / 34)$ of complicated crown fractures and $40 \%(n=25 / 62)$ of uncomplicated crown fractures. Conclusion This study identified marked delays in the management of some paediatric dental trauma to permanent incisor teeth which, in itself, could be suboptimal. Greater educational and clinical support would seem to be warranted in this area of service provision.

\section{EDITOR'S SUMMARY}

There are few more dramatic and tense moments in practice than the child emergency with dental trauma. Anxious parents, a bloodied youngster (perhaps in sports wear), supervisory teachers and a waiting room full of slightly shocked other patients wondering 'what will you be able to do'? - and will it affect their appointment time!

By their nature these accidents are not timed to be predictable or convenient but we nevertheless have to ensure that provision is available to be able to accommodate the necessary reception, examination and treatment in as timely a way as possible. This study points to some potential deficiencies in this, admittedly complex network, through which some paediatric dental patients may fall and looks towards the possibility of developing better co-ordination across dental care pathways and through inter-agency co-operation.
However, central to the findings and recommendations is the matter of better awareness and education for dental professionals and for those likely to be in the front line at the time of trauma. For dental professionals the (hopefully) relative infrequency of such accidents means that a good deal of rapid revision might be needed, which is where the authors' suggested online resources might be of particular value. For nondental personnel their knowledge of the immediate first aid steps can be crucial in the long term prognosis of an injured tooth, especially in the case of avulsion. I believe in fact that teachers have a better record of 'saving' such teeth than dentists, only because of the time factor in replacing or appropriately storing the avulsed tooth.

If we are to continue, quite correctly, educating non-dental personnel in this regard it is also our responsibility to ensure that the appropriate professional back-up is available in a timely way despite the vagaries of dental care delivery modes through different systems. This research may yet play a critical role in ensuring that misplaced hockey sticks, wayward conkers, dare-devil pranks and a whole host of other childhood mishaps do not lead to lost incisors and even more implants.

The full paper can be accessed from the $B D J$ website (www.bdj.co.uk), under 'Research' in the table of contents for Volume 208 issue 6.

Stephen Hancocks, Editor-in-Chief

DOI: 10.1038/sj.bdj.2010.272 


\section{TO ACCESS THE BDJ WEBSITE TO READ THE FULL PAPER:}

- BDA Members should go to www.bda.org.

- Click the 'login' button on the right-hand side and enter your BDA login details.

- Once you have logged in click the 'BDJ' tab to transfer to the BDJ website with full access.

IF YOUR LOGIN DETAILS DO NOT WORK:

- Get a password reminder: go to www.bda.org, click the login button on the right-hand side and then click the forgotten password link.

- Use a recommended browser: we recommend Microsoft Internet Explorer or Mozilla Firefox.

- Ensure that the security settings on your browser are set to recommended levels.

IF YOU HAVE NOT YET SIGNED UP TO USE THE BDA WEBSITE:

- Go to www.bda.org/getstarted for information on how to start using the BDA website.
IN BRIEF

- There is a recognised delay in presentation to tertiary centres following paediatric dental trauma.

- There is a need for paediatric dentistry staff to be proactive in providing regular dental trauma related teaching for their local ActE personnel.

- Priority should be given to more effective teaching to increase knowledge and confidence in dental trauma management.

\section{COMMENT}

Dental trauma is common during childhood and for many injuries, expedient and appropriate management will improve the prognosis. In previous surveys, many did not receive emergency care and treatment was often less than ideal. The aim of the present study was to investigate the delay in emergency care and the appropriateness of treatment. Data were collected prospectively, over an 18-month period for 150 children at three dental hospitals. Nearly half were referred by their GDP, nearly a quarter were self-referrals and the remainder were from medical A\&tE, dental A\&tE and from community services. There were significant mean delays prior to presentation to a health care professional or dental treatment. While the majority were seen promptly, many waited more than 24 hours or 48 hours. The reasons for this delay included prolonged transit time, delays in A\&tE, primary care dentist availability and parental availability. The most common hard tissue injury was an enamel-dentine fracture and next an enamel-dentine pulp fracture. The most common periodontal ligament injury was avulsion. In this hospital derived sample, the vast majority of children received emergency treatment, with complex dental injuries making emergency care more likely as opposed to population based surveys.

According to the criteria drawn up by the study group, many patients were deemed to have received less than optimal treatment. Many uncomplicated crown fractures were found to have inadequate protection of exposed dentine and a large proportion of complicated crown fractures received incorrect pulp management. In terms of avulsion injuries, many children waited between 2.5 and 7.3 hours in A\&E. It appears that the availability and quality of initial care provided for dental trauma in children is still an issue. The initial care provider greatly influenced the appropriateness of the care provided, with a significantly higher proportion of cases being managed appropriately within a dental hospital service under consultant supervision.

In many injuries, the delay prior to the provision of initial treatment is a critical factor in the long term prognosis. In this study a substantial delay was found between injury and treatment of acute paediatric dental trauma and a large proportion of children subsequently received sub-optimal care. Greater education on the management and clinical support is required within primary dental care and A\&tE services to improve management and long term outcomes for children who sustain dental trauma. A large proportion of children sustain significant dental injuries. The findings of the study raise questions about the appropriateness and clarity of the arrangements for the provision of emergency and subsequent treatment for these children.

\section{Kinirons,}

Professor of Paediatric Dentistry, University Dental School and Hospital, Wilton, Cork, Ireland

\section{AUTHOR QUESTIONS AND ANSWERS}

1. Why did you undertake this research? Our Northern Alliance Group, comprising all consultants, specialists and trainees in the Paediatric Dentistry Departments of Liverpool, Manchester and Sheffield Dental Hospitals, had collectively experienced patients attending and reporting delays in their emergency dental trauma management. It was therefore desirable to undertake a multi-centre study to quantify the time lapse to receipt of emergency dental care by paediatric patients. To date this had not been reported for those patients initially seen in primary, secondary or tertiary health care settings. In addition it was important to determine whether the initial management of the injury was appropriate according to the best available evidence from National and International Guidelines.

\section{What would you like to do next in this} area to follow on from this work?

The findings of this study highlight the need for postgraduate teaching for all professionals who may be required to provide initial care for dental trauma management. Our aim is to develop and pilot a local online dental trauma module which can be accessed by healthcare professionals and school staff. If the pilot scheme proved successful, the teaching could be rolled out nationally. In addition, we believe there is merit in developing a nationwide trauma hotline to support healthcare professionals undertaking initial dental trauma management. Our intention is to investigate the feasibility and efficacy of providing this service to improve the management of paediatric dental trauma. 